\title{
PROTÓTIPO DE UM HARDWARE EDUCACIONAL PORTÁTIL E DE BAIXO CUSTO PARA O ENSINO DE ELETRICIDADE E ELETRÔNICA
}

Cícero J M N da Silva - cicerojosean@ yahoo.com.br

Universidade Federal do Rio Grande do Norte

Campus Universitário Lagoa Nova

59078-970 - Natal - Rio Grande do Norte

Luiz Affonso Guedes - affonso@ dca.ufrn.br

Universidade Federal do Rio Grande do Norte

Campus Universitário Lagoa Nova

59078-970 - Natal - Rio Grande do Norte

Resumo: A separação entre o estudo da teoria e a realização de aulas práticas no ensino de disciplinas de eletricidade e eletrônica sempre foi um desafio em cursos de engenharia. Essa dificuldade normalmente se deve ao fato de alguns instrumentos utilizados nos experimentos serem caros e inacessíveis para aquisição ou uso em qualquer momento para a maior parte dos alunos, e, assim, estarem disponíveis somente nos laboratórios das instituições. Fato esse faz com que os estudantes só tenham acesso a eles em momentos específicos e limitados. Isso também impossibilita a execução de experimentos em casa, dificultando, portanto, a possibilidade de atividades práticas a distância. Diante desta realidade, este trabalho apresenta o desenvolvimento de um protótipo de um hardware educacional portátil e de baixo custo, comandado por um software embarcado em celular (também desenvolvido no projeto) para suporte às atividades experimentais de eletricidade e eletrônica. Esse dispositivo une as principais funcionalidades de um osciloscópio e de um gerador de sinais tradicionais (que geralmente são os equipamentos mais caros utilizados em experimentos básicos), possibilitando, assim, a realização dessas práticas em ambientes fora do laboratório. Os resultados preliminares se apresentam positivos, já que o dispositivo conseguiu realizar os objetivos propostos, e indica que pode ser utilizado por alunos para a montagem de experimento básicos em casa, ao mesmo tempo em que estudam a teoria indicado pelos professores.

Palavras-chave: Osciloscópio. Gerador de sinais. Experimentos.

\section{INTRODUÇÃO}

O ensino de conceitos básicos de eletricidade e de eletrônica é comum no ensino superior em cursos de engenharia, sobretudo no curso de engenharia elétrica. Estes conteúdos, além de notadamente serem de difícil compreensão, são pouco demonstrados por meio de atividades práticas em alguns cursos e instituições. Um dos fatores que podem contribuir para essa 
realidade é a limitação do uso dos laboratórios, devido à grande quantidade de alunos que precisam utilizá-los e à escassez de equipamentos disponíveis para uso.

Componentes usados em experimentos no ensino de eletrônica e eletricidade geralmente são de baixo custo, como por exemplo: resistores, capacitores, protoboard, fios, botões, diodos e LEDs. Contudo equipamentos eletrônicos utilizados em conjunto que permitem geração e medição de alguma grandeza elétrica têm um custo bem mais elevado, tais como: geradores de funções, fontes de alimentação e osciloscópio. Isso dificulta tanto a aquisição de equipamentos em grandes quantidades, dependendo dos recursos financeiros de cada instituição, quanto a possibilidade de os alunos adquirirem tais equipamentos para uso pessoal. Esses fatores vão de encontro a uma tendência atual do ensino, que é a educação semipresencial e a educação a distância. Assim, a realização de experimentos práticos de modo remoto tende a se tornar inviável nesse contexto.

Por outro lado, com o avanço dos aparatos tecnológicos e a adoção de metodologias ativas no ensino superior, é possível sempre se pensar em modos de contornar dificuldades existentes em sala de aula, que no caso específico abordado nesse artigo são relacionadas às práticas experimentais. As metodologias ativas são estratégias pedagógicas que criam um cenário em torno do aluno, de modo que eles sejam mais engajados no seu aprendizado (VALENTE et al, 2017). Uma tendência de utilização da tecnologia a favor da educação como forma de auxílio da aprendizagem é o uso de dispositivos móveis, como, por exemplo, um smartphone. Moran (2018, p.51) cita que "a combinação de metodologias ativas com tecnologias digitais móveis é hoje estratégica para a inovação pedagógica".

O trabalho apresentado no presente artigo relata o desenvolvimento do protótipo de um hardware educacional portátil e de baixo custo para auxílio no ensino de práticas básicas de eletricidade e eletrônica. O protótipo é capaz de combinar funções simples de dois instrumentos bastante utilizados em experimentos em eletricidade e eletrônica: osciloscópio e gerador de sinais. O hardware desenvolvido se comunica com o usuário por meio de um aplicativo criado para a plataforma Android, que utiliza comunicação bluetooth. O desenvolvimento desse instrumento busca possibilitar a realização de experimentos simples de eletricidade e eletrônica em ambientes fora da sala de aula, permitindo que os alunos pratiquem ao mesmo tempo em que aprendem conceitos teóricos em casa, por exemplo. Os resultados foram obtidos com teste em circuitos simples e utilizando instrumentos comerciais para validação.

O restante do artigo apresenta como são as práticas de eletricidade e eletrônica, enfatizando os equipamentos usados em laboratório que são abordados no protótipo e relata alguns outros trabalhos relacionados a esse projeto. Posteriormente é apresentada a proposta do hardware educacional, enfatizando o módulo gerador de sinais e o módulo osciloscópio. A seguir são mostrados os resultados obtidos e por fim as considerações finais.

\section{PRÁTICAS DE ELETRICIDADE E ELETRÔNICA}

Os experimentos iniciais e básicos de eletricidade e eletrônica abordam geralmente o estudo e uso de componentes usados em grande parte dos circuitos elétricos: resistores, capacitores, indutores, diodos, transistores, dentre outros. As práticas laboratoriais são importantes para ajudar os estudantes no entendimento mais claro dos conceitos estudados na teoria. E também é o local onde eles podem manusear componentes e equipamentos que possivelmente irão se deparar em sua vida profissional.

Essas aulas práticas iniciais geralmente abordam e mostram aplicações das leis de Ohm, circuitos de corrente contínua e alternada, retificação de onda alternada, carga e descarga de 
capacitor, e assim por diante. Dependendo do experimento, são necessários instrumentos como osciloscópio, gerador de funções, multímetro e fonte de alimentação.

\subsection{Equipamentos Típicos}

Dois dos principais equipamentos utilizados em práticas de eletricidade e eletrônica são o osciloscópio e o gerador de funções. Versões comerciais desses dois instrumentos estão sendo mostrados na Figura 1.

Osciloscópio é um instrumento essencial para a prática de projetos e manutenção de sistemas eletrônicos, pois permite visualizar formas de onda de sinais elétricos e analisar alguns parâmetros importantes como amplitude e frequência (MUNDO DA ELETRÔNICA, 2020). Ele é usado, por exemplo, na manutenção de equipamentos eletrônicos, projeto de equipamentos e circuitos, identificação de defeitos em sistemas eletrônicos, análise da rede elétrica. Para a realidade econômica da maioria dos alunos do país, o osciloscópio é um equipamento considerado de alto custo, sendo encontrado normalmente com preço acima de $\mathrm{R} \$ 1.500$. O gerador de funções, também conhecido como gerador de sinais, é um equipamento usado para gerar sinais elétricos de frequências, amplitude e formas de onda ajustáveis. Os tipos mais comuns de formas de onda geradas são: senoidais, triangulares e quadradas. São muito utilizados em laboratórios para calibragem e reparo de circuitos eletrônicos, geralmente em conjunto com o osciloscópio (BAÚ DA ELETRÔNICA, 2020). É um equipamento encontrado no mercado custando acima dos $\mathrm{R} \$ 1.000,00$.

Figura 1 - Exemplo de um osciloscópio e de um gerador de sinais
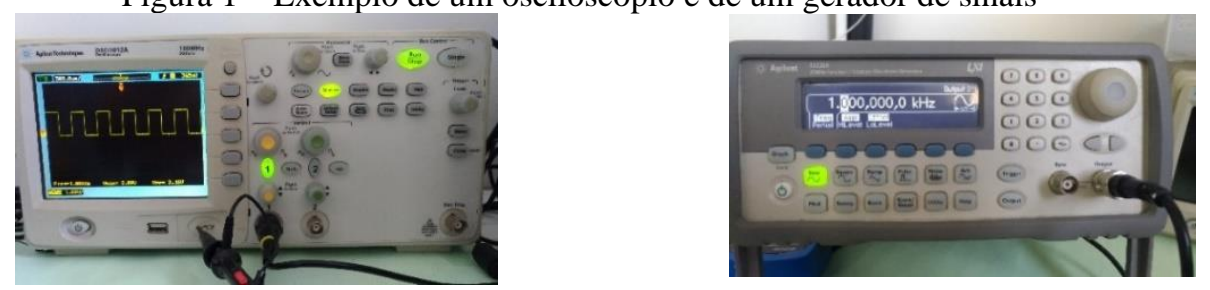

Fonte: Autoria Própria

\subsection{Trabalhos Relacionados}

A pesquisa por trabalhos relacionados busca servir de subsídio para o desenvolvimento da nossa proposta. As bases de pesquisa consultadas foram: Portal Periódicos CAPES/MEC, a Biblioteca Digital Brasileira de Teses e Dissertações (BDTD), Scientific Electronic Library Online (SciELO) e a Scopus/Elsevier. Priorizou-se trabalhos que utilizaram sistemas microcontrolados da família ESP, tanto para a construção de dispositivos de medição (osciloscópio, multímetro, gerador de sinais), como os que foram elaborados para utilização didática. Definiu-se também a seleção dos trabalhos publicados em língua portuguesa, inglesa e espanhola, com prioridade a periódicos revisados por pares.

A pesquisa nos diversos portais indicou que a maioria dos resultados encontrados utilizava instrumentos comerciais (osciloscópio, multímetro e gerador de funções), portanto fugindo da ideia desse trabalho que é a construção de um protótipo de baixo custo para substituir esses equipamentos. Em alguns desses trabalhos, propôs-se a prototipação de gerador de sinais, mas usam componentes digitais e modos de construção diferentes do proposto aqui, e, além disso, não usam microcontroladores, não sendo, assim, aplicáveis a esse projeto. Os trabalhos de Pilicita-Garrido e Cevallos-Duque (2019), e de Diniz et al. (2017) tratam da criação de um dispositivo (sistema de monitoramento de energia e medidor digital de energia, respectivamente), porém utilizam sensores (não usados neste trabalho) para aquisição de dados 
e utilizaram microcontrolador PIC. Trabalhos como os de Kochlan et al. (2016), Ruiz e Cardenas (2016) mostram o desenvolvimento de um osciloscópio portátil (ou similar), envolvendo alguns dos temas buscados nesse projeto de pesquisa: portabilidade, uso de smartphone, conexão bluetooth e de microcontroladores. Porém são soluções mais complexas e mais caras, que não seguem a ideia inicial desse trabalho.

O trabalho mais relevante nessa base de pesquisa para o nosso contexto foi o de Osisiogu (2018). Neste projeto, um osciloscópio barato e acessível foi projetado e construído com o uso de um Arduino, a fim de garantir a disponibilidade de ferramentas para amadores, pesquisadores e estudantes para projetos e pesquisas eletrônicas. Maier et al. (2017) fornece uma análise comparativa do ESP32 com alguns outros concorrentes do mercado, além de apresentar a especificação do microcontrolador, recursos e detalhes de programação. Apresenta ainda formas de utilização como osciloscópio portátil e sem fio. Já Muñoz-Rodrigues et al. (2014) apresenta uma implementação de um aplicativo (feito no software Orcad Pspice) que consegue controlar através da Internet uma bancada básica de laboratório de eletrônica.

O protótipo apresentado nesse artigo tem características mais simples que alguns vistos na literatura, já que o objetivo é servir como um dispositivo para realização de atividades básicas. Porém, essa característica faz com que o protótipo tenha um custo bem mais baixo e com a possibilidade de replicação e uso maior, e também de possíveis melhorias e adaptações.

\section{PROPOSTA DO HARDWARE EDUCACIONAL}

O dispositivo apresentado nesse artigo visa diminuir o distanciamento entre o estudo da teoria e das atividades práticas básicas de eletricidade e eletrônica. Isso é possível pelo fato dele ser portátil e de baixo custo, dando possibilidade do seu uso em práticas laboratoriais em locais fora da sala de aula, no conceito de um-dispositivo-por-aluno. A proposta é que o dispositivo possa ser usado em substituição (em experimentos básicos), de forma simples e barata, a instrumentos essenciais e disponíveis normalmente somente em laboratórios. Assim, não é necessário que somente em horários específicos os alunos possam realizar as práticas, e sim em diversos outros momentos, por exemplo ao mesmo tempo em que eles estão estudando a teoria em casa. Componentes mais simples necessários para a montagem dos circuitos (protoboard, resistores, diodos, etc.) seriam disponibilizados temporariamente pela instituição para os alunos (ou comprados pelos mesmos, caso desejem) de forma a montarem os experimentos.

$\mathrm{O}$ aparato desenvolvido agrupa algumas funcionalidades de geradores de sinais e de osciloscópios, que são necessárias para a realização de alguns experimentos. No projeto foi utilizado como componente central a placa de desenvolvimento DOIT ESP32, que conta com o chip ESP32, um microcontrolador da Espressif (ESPRESSIF SYSTEMS, 2020). Além dele, foi utilizado um display LCD SSD1306, que é o responsável por mostrar as formas de onda lidas pelo módulo osciloscópio.

Para o controle do hardware, é utilizado um software desenvolvido nesse projeto para a plataforma Android, e que pode ser utilizado em grande parte dos smarphones e tablets disponíveis comercialmente. Esse software foi desenvolvido utilizando a ferramenta online MIT APP Inventor, da Massachusetts Institute of Technology. A comunicação entre o aplicativo e o hardware é feita através da comunicação bluetooth. Portanto, para colocar o dispositivo em funcionamento é necessário realizar essa conexão entre ele e o celular. Após essa conexão ser realizada com sucesso, os comandos disponíveis no aplicativo agem diretamente no microcontrolador. 


\subsection{Módulo Gerador de Sinais}

Um diagrama de blocos desse módulo é mostrado na Figura 2, ilustrando o desenvolvimento do dispositivo. Os parâmetros do gerador de sinais são definidos pelo usuário através de um aplicativo de celular (sistema operacional Android), desenvolvido também nesse projeto.

Figura 2 - Diagrama de Blocos do Módulo Gerador de Sinais.

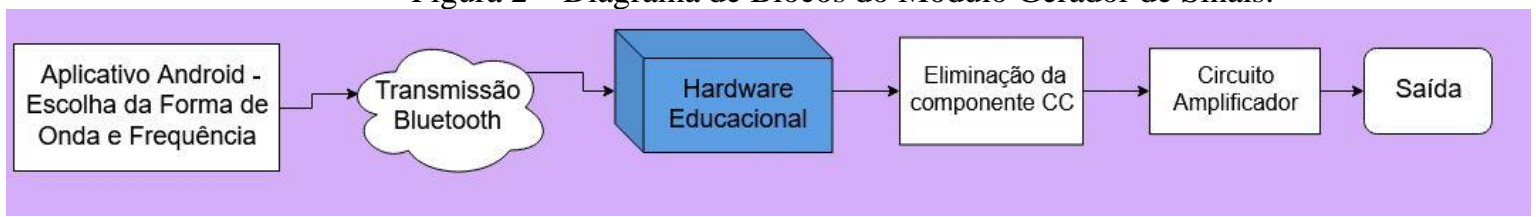

Fonte: Autoria Própria

O módulo gerador de funções foi projetado para ser capaz de gerar quatro tipos de formas de onda: senoidal, quadrada, triangular e dente-de-serra. A faixa de trabalho foi definida de $60 \mathrm{~Hz}$ a $1.200 \mathrm{~Hz}$. Pelo aplicativo do celular, o usuário é capaz de escolher a frequência tanto por alguns valores já pré-definidos como através de um slider, que percorre entre os dois valores limites. Nesse projeto foi utilizada uma saída Digital-Analógica (DAC) do ESP32 (pino 25) para disponibilizar na saída um sinal analógico mais real, deixando o dispositivo mais próximo do equipamento comercial. Para criar a onda desejada, utilizaram-se no código de programação do microcontrolador matrizes bidimensionais, cujos valores se repetem de acordo com uma frequência definida. Essa abordagem foi baseada na utilizada por Fernando Koyanagi (2020).

Por características do microcontrolador, a saída gerada pelo ESP32 só possui ciclo positivo. Um circuito externo acoplado à saída do pino 25 do microcontrolador foi necessário para tornar a saída uma onda com polaridade tanto positiva quanto negativa (que é o que acontece em um gerador de sinais tradicional). Esse circuito remove a componente DC do sinal, tornando-o, assim, totalmente AC, com semiciclos positivo e negativo. A Figura 3 ilustra um exemplo da saída diretamente do pino 25 do ESP32, e após o circuito de correção. Também foi adicionado ao módulo uma etapa de amplificação com ajuste, como o intuito de o circuito de saída possuir um valor mais elevado de tensão. Para isso, foi utilizado um circuito amplificador baseado no CI LM358. Com o uso de um potenciômetro, o usuário consegue regular essa amplificação.

Figura 3 - Saída do módulo Gerador de Sinais sem e com o circuito de correção

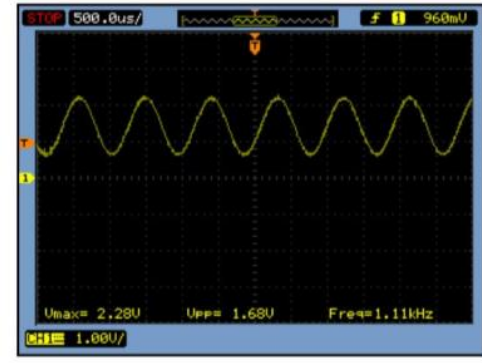

Fonte: Autoria Própria

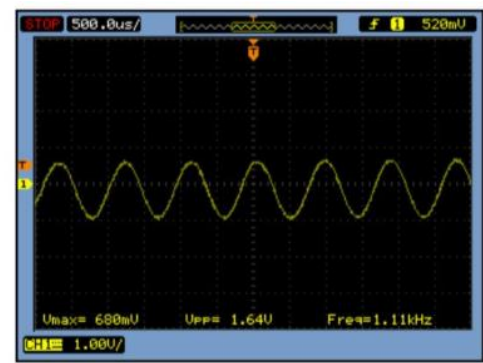

\subsection{Módulo Osciloscópio}

Esse módulo possui a função de visualização da forma de onda que é inserida em uma de suas duas entradas. Na primeira entrada, que é para tensões de no máximo $3 \mathrm{~V}$ pico-a-pico, o sinal é acrescido de um nível DC antes de ser inserido na entrada analógica do microcontrolador. Isso é necessário pois o ESP32 não permite a entrada de tensões negativas. 


\section{COBENGE C. COBENGE 2020 \\ de Educaçāo em Engenharia da ABENGE}

No caso de tensões maiores que $3 \mathrm{~V}$, que nos experimentos básicos de eletricidade é usada a alimentação da rede elétrica $(110 \mathrm{~V} / 220 \mathrm{~V})$, o sinal necessita de uma etapa a mais: redução da amplitude da tensão elétrica. Isso é realizado por um circuito divisor de tensão, composto de um transformador e um conjunto de resistores, que conseguem reduzir até o nível seguro para não exceder os $3 \mathrm{~V}$ pico-a-pico. Após essa etapa, o sinal é acrescido de um sinal CC para elevar o ciclo negativo, e, assim, poder ser injetado no microcontrolador. O diagrama de blocos descrevendo essas funcionalidades é mostrado na Figura 4.

Figura 4 - Diagrama de Blocos do Módulo Osciloscópio.

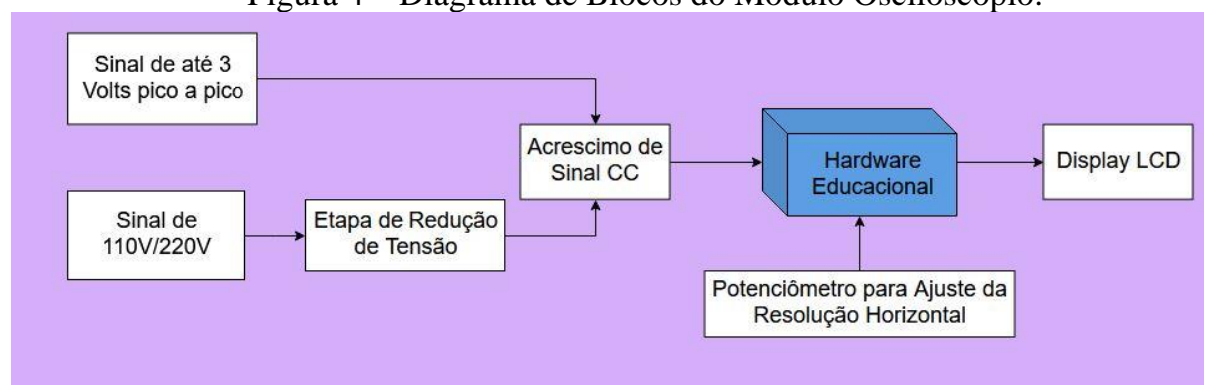

Fonte: Autoria Própria

Pelo aplicativo instalado no celular smartphone é possível ativar a visualização do sinal desejado, bem como pausar a forma de onda. Também por ele é selecionada qual entrada analógica é ativada para a visualização do sinal. O ajuste da resolução horizontal da onda é realizado no próprio hardware, com o uso de um potenciômetro. Assim, dependendo da frequência do sinal, é realizado o ajuste por ele para se obter uma melhor visualização. O LCD SSD1306 é o responsável por mostrar o sinal no módulo osciloscópio. Esse display tem 0,96 polegadas e resolução de 128x64 pixels, e utiliza o protocolo I2C para comunicação com o microcontrolador. A Figura 5 mostra o esquema de ligação desse módulo.

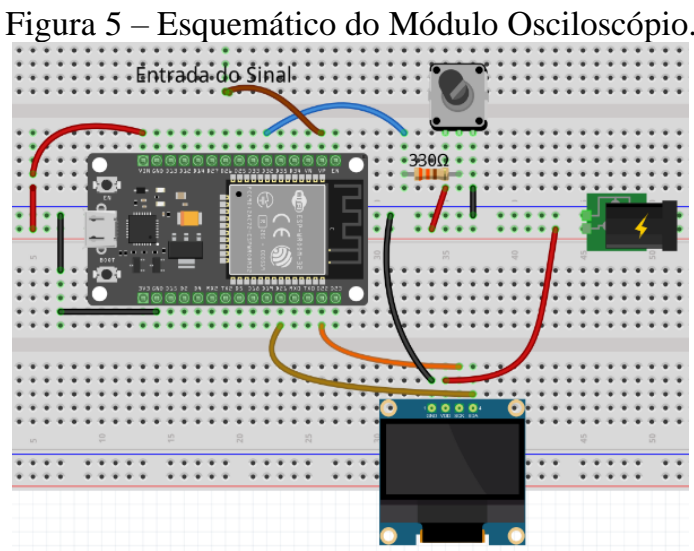

Fonte: Autoria Própria 


\section{RESULTADOS}

A tela inicial desse aplicativo, que é executado no celular smartphone, é mostrada na Figura 6. Nessa figura também são representadas as telas dos módulos Gerador de Sinais e Osciloscópio.

Figura 6 - Tela dos Aplicativo desenvolvido
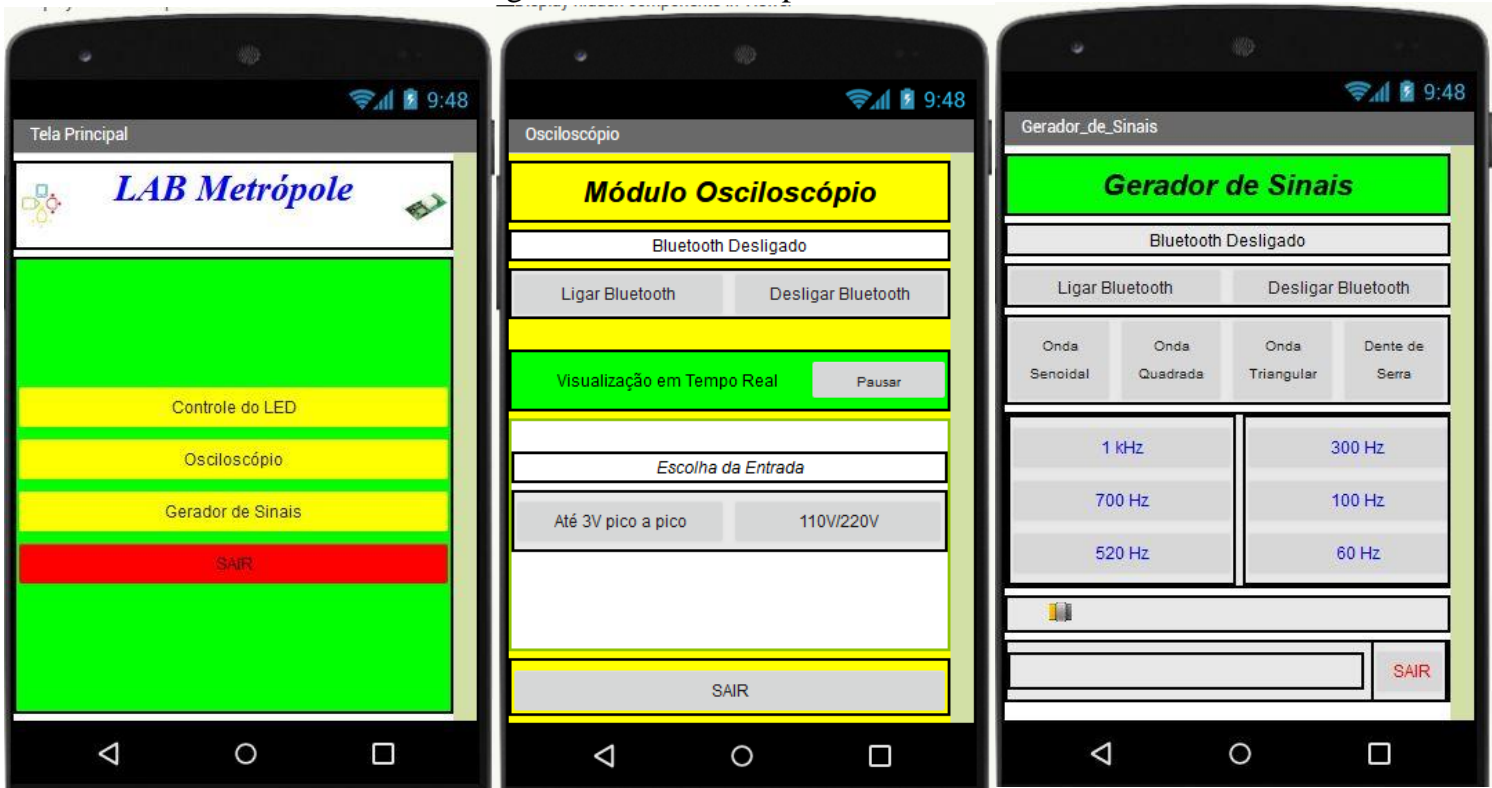

Fonte: Autoria Própria

O teste de validação do gerador de funções foi realizado com a visualização dos sinais gerados pelo protótipo em um osciloscópio comercial. Algumas formas de onda estão representadas na Figura 7. Na Tabela 1, estão apresentados os valores de tensão máximo e mínimo de acordo com o tipo de onda escolhida.

Figura 7 - Formas de ondas geradas pelo módulo Gerador de Sinais

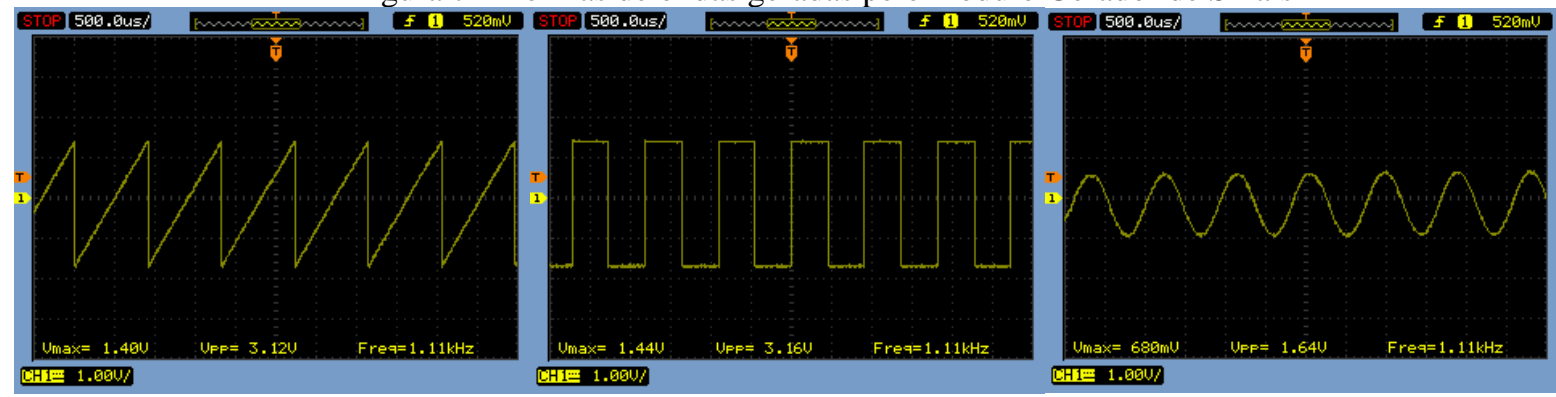

Fonte: Autoria Própria

Tabela 1 - Formas de onda obtidas no módulo Gerador de Sinais

\begin{tabular}{c|c|c|}
\hline Forma de Onda & Valor Mínimo (pico a pico) & Valor Máximo (pico a pico) \\
\hline Senoidal & $1.58 \mathrm{~V}$ & $9.20 \mathrm{~V}$ \\
\hline Quadrada & $3.20 \mathrm{~V}$ & $11 \mathrm{~V}$ \\
\hline Triangular & $3.06 \mathrm{~V}$ & $9.12 \mathrm{~V}$ \\
\hline Dente de Serra & $3.06 \mathrm{~V}$ & $9.12 \mathrm{~V}$ \\
\hline
\end{tabular}

Fonte: Autoria Própria 
Para teste de validação do funcionamento do módulo osciloscópio, foram geradas formas de onda senoidal, quadrada e dente de serra por um osciloscópio comercial (Agilent 33220A). Os sinais lidos e mostrados pelo protótipo estão apresentados na Figura 8.

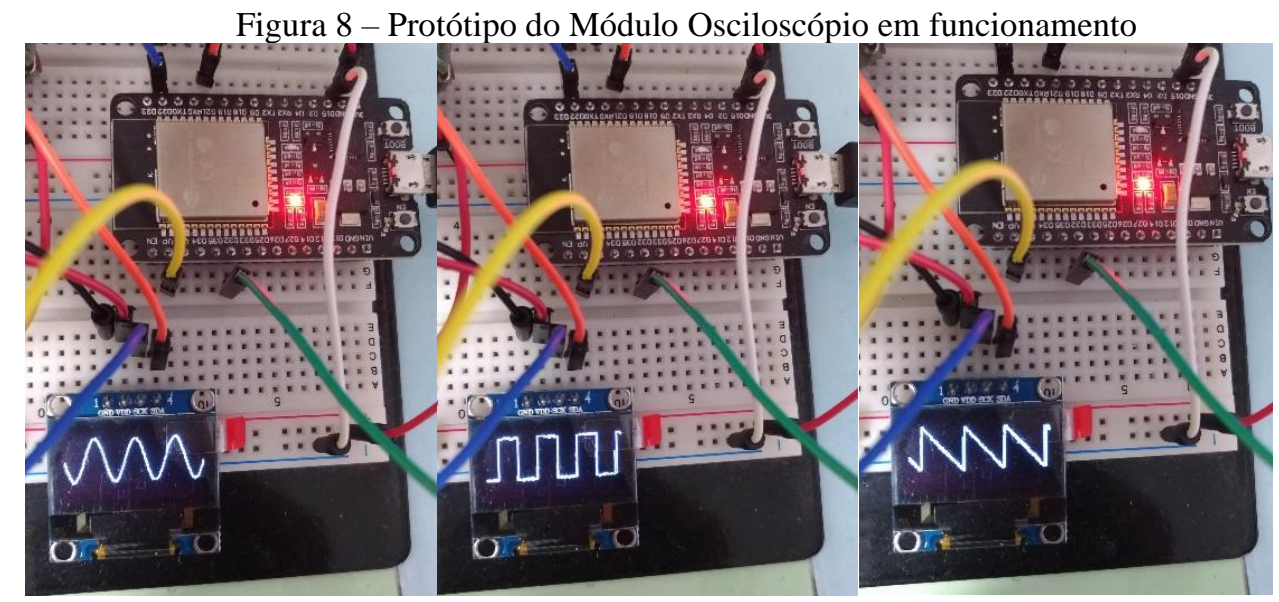

Fonte: Autoria Própria

O circuito do protótipo montado está representado na Figura 9.

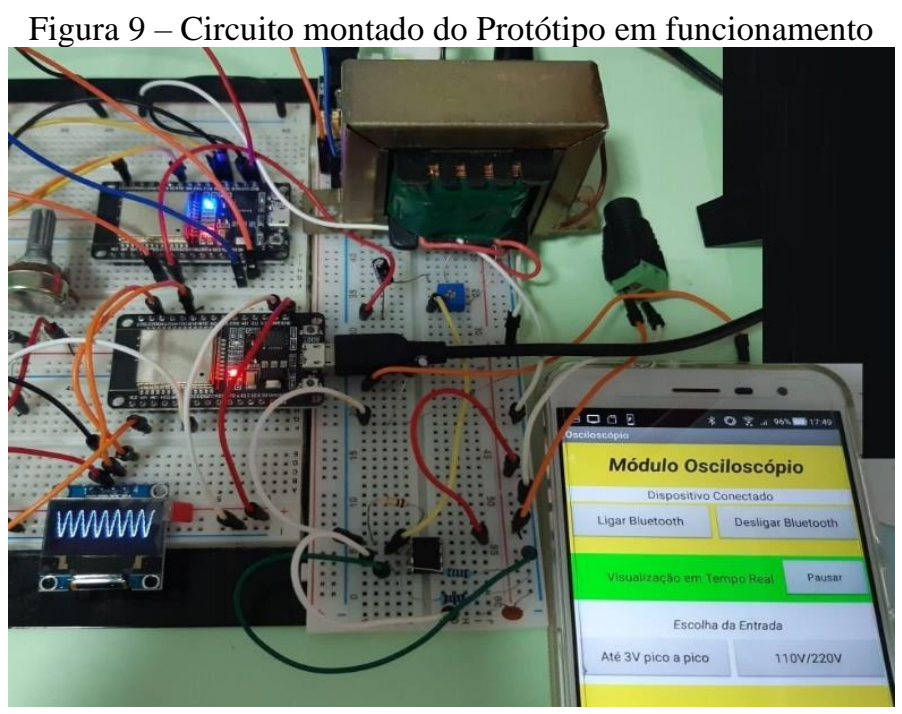

Fonte: Autoria Própria

\section{CONSIDERAÇÕES FINAIS}

Devido ao estado em que a sociedade vive atualmente por conta da pandemia da COVID19 e a suspensão das aulas, não foi possível ainda realizar o teste envolvendo um grupo de alunos. Esse passo será realizado em uma etapa seguinte, e os resultados serão levantados e analisados para uma melhor compreensão dos benefícios e limitações do produto, para, a seguir, serem desenvolvidos avanços no projeto.

O protótipo desenvolvido apresenta como vantagem principal o fato de ser uma alternativa que possibilita a realização de experimentos fora do ambiente laboratorial. Assim, o aluno pode ao mesmo tempo que estuda a teoria em casa, realizar também atividades práticas simples. $\mathrm{O}$ 
distanciamento e às vezes até a dissociação entre a teoria e prática, sempre dita como um problema, pode ser diminuída com isso.

Outro ponto positivo é o custo do dispositivo. O protótipo teve um custo aproximado entre $\mathrm{R} \$ 50$ e $\mathrm{R} \$ 60$, levando-se em conta os componentes utilizados para a sua construção. Os componentes mais caros foram o kit de desenvolvimento ESP32, que custa entre R $\$ 20$ e $R \$ 30$, e o display LCD, que custa entre $\mathrm{R} \$ 10$ e $\mathrm{R} \$ 20$.

Por se tratar de um dispositivo simples, já que o intuito é de ser um produto barato e acessível, faz com que o mesmo tenha algumas limitações. As medições dele não são tão precisas quanto de equipamentos comerciais, e não possui tanta robustez e quantidade de funcionalidades quanto de osciloscópios e geradores de funções tradicionais. Porém, para experimentos simples, em que os alunos estão tendo o primeiro contato com os conceitos e práticas de eletricidade e eletrônica, acreditamos que o artefato seja suficiente.

O dispositivo pode ser utilizado por alunos que cursem disciplinas iniciais de eletricidade e eletrônica em cursos de engenharia, como também em cursos técnicos e profissionalizantes que ofertem disciplinas que envolvam circuitos elétricos e eletrônicos.

Algumas melhorias podem ser introduzidas no protótipo. Uma delas é a adição de um segundo canal para o módulo osciloscópio, de modo a ter a possibilidade de visualização de duas formas de onda ao mesmo tempo. Outra melhoria recomendada, e que será realizada futuramente, é a adição de estágios de proteção para o aparato. Pretende-se, também, o desenvolvimento de um aplicativo para a plataforma iOS (sistema operacional móvel da Apple Inc.), que junto com o aplicativo já desenvolvido para a plataforma Android, serão disponibilizados gratuitamente aos usuários.

\section{REFERÊNCIAS}

BAÚ DA ELETRÔNICA. Gerador de Função. Disponível em: https://www.baudaeletronica.com.br/ferramentas/instrumentos-de-medicao/gerador-defuncao. Acesso em: 5 jul. 2020.

DINIZ, B. R. A; EVANGELISTA, A. A.; ALEXANDRIA, A. R.. Projeto e desenvolvimento de um medidor digital de energia elétrica monofásico para aplicações residenciais. Holos, Natal, v. 7, n. 1, p. 55-68, nov./2017.

KOCHLAN, M. et al. Multichannel Recorder for Low Frequency Signals: application of Oscilloscope as Integrated Mobile Service for a Smartphone. Hindawi, Slovakia, v. 2016, n. 1, p. 1-7, abr./2016.

MAIER, Alexander; SHARP, Andrew; VAGAPOV, Yuriy. Comparative Analysis and Practical Implementation of the ESP32 Microcontroller Module for the Internet of Things. Internet Technologies and Applications (ITA), Wrexham, v. 1, n. 1, p. 143-148, set./2017.

MORAN, José. Metodologias ativas para uma educação inovadora: uma abordagem teórico-prática. 1. ed. Porto Alegre: Penso, 2018. p. 1-401.

MUNDO DA ELÉTRICA. O que é osciloscópio e para que serve?. Disponível em: https://www.mundodaeletrica.com.br/o-que-e-osciloscopio-e-para-que-serve/. Acesso em: 5 jun. 2020. 
MUÑOZ-RODRÍGUEZ, F. J. et al. Web app for a Remote Electronics Instrumentation Lab. XI Tecnologias Aplicadas a la Ensenanza de la Electronica (Technologies Applied to Electronics Teaching) (TAEE), Bilbao, v. 1, n. 1, p. 1-6, nov./2014.

OSISIOGU; UKACHI. Undergraduate Project on The Design and Construction of an Arduino Based Oscilloscope. African University of Science and Technology, Nigéria, v. 1, n. 1, p. 1110 , set./2015.

PILICITA-GARRIDO, A. E.; CEVALLOS-DUQUE, D. C.. Innovación tecnológica de un sistema integral para monitorear el consumo eléctrico. Ingenius, Equador, v. 1, n. 22, p. 9-16, abr./2019.

RUIZ, Pablo Jacome; CARDENAS, Cristiam Baquerizo. Monitor Cardíaco Portátil con Interfaz Bluetooth "CARDIO UEES”. Revista Ciencia UNEMI, Equador, v. 9, n. 20, p. 3649 , set./2016.

VALENTE, José Armando; ALMEIDA, M. E. B. D; GERALDINI, A. F. S. Metodologias ativas: das concepções às práticas em distintos níveis de ensino. Diálogo Educ., Curitiba, v. 17, n. 52, p. 455-478, abr./2017.

\title{
PROTOTYPE OF A LOW-COST PORTABLE EDUCATIONAL HARDWARE FOR ELECTRICITY AND ELECTRONIC TEACHING
}

\begin{abstract}
The separation between the study of theory and the realization of practical classes in the teaching of electricity and electronics disciplines has always been a challenge in engineering courses. This difficulty is usually due to the fact that some instruments used in the experiments are expensive and inaccessible to purchase or use at any time for most students, and thus are only available in the laboratories of the institutions. This fact means that students only have access to them at specific and limited times. This also makes it impossible to carry out experiments at home, making it difficult, therefore, the possibility of practical activities at a distance. In view of this reality, this work presents the development of a prototype of a low cost and portable educational hardware, commanded by software embedded in a cell phone (also developed in the project) to support the experimental activities of electricity and electronics. This device unites the main features of traditional oscilloscopes and signal generators (which are generally the most expensive equipment used in basic experiments), thus making it possible to carry out these practices in environments outside the laboratory. The preliminary results are positive, because the device was able to achieve the proposed objectives, and indicates that it can be used by students to set up basic experiments at home, while studying the theory indicated by teachers.
\end{abstract}

Keywords: Oscilloscope. Signal generator. Experiments. 